\title{
Mitochondrial calcium: a crucial hub for cancer cell metabolism?
}

\author{
Wolfgang F. Graier, Roland Malli \\ Institute of Molecular Biology and Biochemistry, Medical University of Graz, Graz, Austria \\ Correspondence to: Wolfgang F. Graier, PhD. Chair and Full Professor of Molecular Biology, Institute of Molecular Biology and Biochemistry, Medical \\ University of Graz, Neue Stiftingtalstrasse 6/6, 8010 Graz, Austria. Email: wolfgang.graier@medunigraz.at. \\ Comment on: Chakraborty PK, Mustafi SB, Xiong X, et al. MICU1 drives glycolysis and chemoresistance in ovarian cancer. Nat Commun \\ $2017 ; 8: 14634$
}

Submitted Aug 04, 2017. Accepted for publication Aug 14, 2017.

doi: $10.21037 /$ tcr.2017.08.28

View this article at: http://dx.doi.org/10.21037/tcr.2017.08.28

\section{Introduction}

According to the current concept, a typical tumor contains "driver gene" mutations that establish a growth advantage to the tumor cell (1). It was proposed that one of the first mutations must have either a mutation that introduces a selective growth advantage to a normal cell (1) or one of the first mutations results in genomic instability, thus, increasing the chance for the accumulation of further mutations (2). Recent data indicate that metabolic reprogramming by (somatic) mutations of key metabolic genes promotes cancer growth (3). In this context metabolic adaptations upon aging need to be considered as hallmark of cancer (4). Since the landmark discovery of cancerspecific enhancement of glycolysis with concurrent small respiration (5), abnormalities in mitochondrial functions as a key phenomenon of the metabolic peculiarities of cancer cells has been postulated. Otto Warburg assumed that the accumulation of lactate in cancer tissue is the result of enhanced anaerobic glycolysis and dysfunctional mitochondrial respiration. This assumption was lately challenged by still controversial findings of a reduced conversion of phosphoenolpyruvate to pyruvate by the less active, cancer-specific isoform pyruvate kinase 2 (PKM2) (6), which might limit the production of ATP from glycolysis, but boosts the accumulation of intermediate products like nucleic acids and phospholipids for cancer cell growth (7). Nevertheless, Otto Warburg was prophetic in his view on the role of metabolism for cancer. Recent work highlights alterations of mitochondria-associated genes to play an essentially role in the metabolic reprogramming in cancer cells that play a supportive, if not causative role in tumorigenesis (8). The latter hypothesis was stressed by a recent work where mitochondria/cytosolic transfer from a cancer cell into a somatic cell turned the latter one to a cancer cell as well (9). While the interpretation of this work is complex, mitochondrial metabolic and signal functions that undergo a cancer-specific transformation (4) involving mitochondria-endoplasmic reticulum (ER) settings $(10,11)$ are known to be essential to meet the enhanced energy demand of a cancer cell. The study "MICU1 drives glycolysis and chemoresistance in ovarian cancer" by Chakraborty et al. recently published in Nature Communications (12) describes important new findings supporting the current hypothesis on mechanistic/ functional mitochondrial adaptations to be crucial for cancer cell development. Importantly this work points to a crucial role of mitochondrial calcium uptake 1 (MICU1), the gatekeeper of mitochondrial $\mathrm{Ca}^{2+}$ uniport (MCU) (13), for glycolysis and chemoresistance in ovarian cancer. Notably, this work considerably fuels current hypothesis on the importance of mitochondrial $\mathrm{Ca}^{2+}$ uptake for cancer cell survival and growth $(10,11,14)$ and points to adaptations in mitochondrial $\mathrm{Ca}^{2+}$ as a hallmark in the adjustment of mitochondrial activity in cancer cells.

\section{All about mitochondrial calcium?}

Chakraborty and coworkers also described an obvious role of MICU1 in the regulation of pyruvate dehydrogenase (PDH) by affecting the phosphoPDH: PHD ratio. They further describe a strong impact of MICU1 depletion on the anti-tumor effects of cisplatin. Notably, these particular findings were acquired under conditions of MICU1 


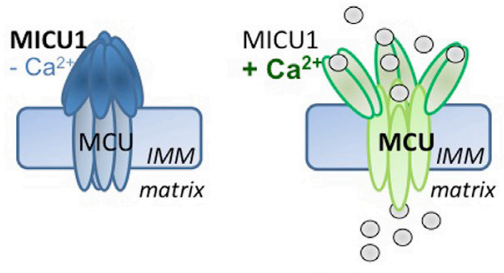

MICU1 controlled mitochondrial $\mathrm{Ca}^{2+}$ uptake
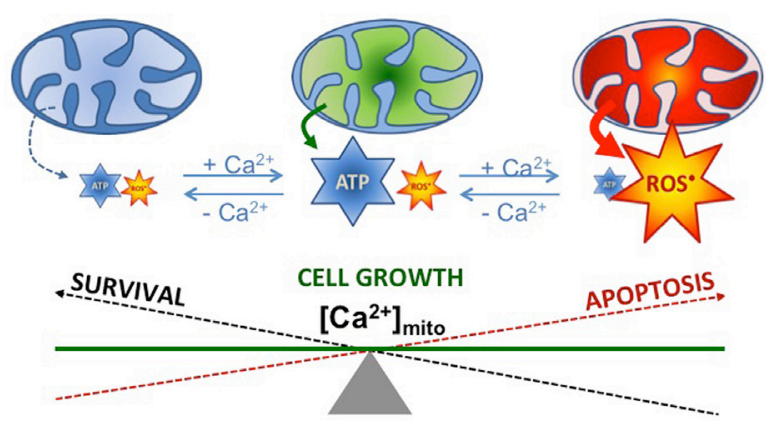

Figure 1 ATP and ROS production is under the control of mitochondrial $\mathrm{Ca}^{2+}$ uptake. MICU1 prevents mitochondrial $\mathrm{Ca}^{2+}$ loading under resting conditions (left blue panels). Physiological $\mathrm{Ca}^{2+}$ signals activate $\mathrm{MCU}$ via $\mathrm{Ca}^{2+}$ binding to MICU1, which allows controlled mitochondrial $\mathrm{Ca}^{2+}$ sequestration and consequently stimulates mitochondrial ATP production (middle green panels). Diminished MICU1 expression levels can lead to an uncontrolled mitochondrial $\mathrm{Ca}^{2+}$ overload, which has the potency to trigger enhanced ROS production and cell death pathways (right red panels). MICU1, mitochondrial calcium uptake 1; MCU; mitochondrial $\mathrm{Ca}^{2+}$ uniport.

silencing, conditions where mitochondrial $\mathrm{Ca}^{2+}$ uptake is strongly enhanced (12), due to the protein's gatekeeper function in most cells (15). Hence, because the activity of the mitochondrial oxidative phosphorylation (OXPHOS) crucially depends on $\mathrm{Ca}^{2+}$-dependent dehydrogenases in the citrate cycle in the mitochondrial matrix, $\mathrm{Ca}^{2+}$ acts a main regulator for mitochondrial ATP synthesis (16), thus, a regulatory role of mitochondrial $\mathrm{Ca}^{2+}$ appears likely even in case of PDH activity (17). Such central role of mitochondrial $\mathrm{Ca}^{2+}$ in the regulation of mitochondrial processes and function appears a consequence of the tight physical and functional coupling of ER-released $\mathrm{Ca}^{2+}$ and mitochondrial $\mathrm{Ca}^{2+}$ sequestration. Recently, an optimized physical coupling between the ER and mitochondria was described in cancer cells $(10,11)$. Notably, while the constitutive $\mathrm{Ca}^{2+}$ flux from the ER to mitochondria was demonstrated to be essential to maintain viability of cancer cells with high proliferation activity (10), mitochondrial $\mathrm{Ca}^{2+}$ overload (Figure 1) due to e.g., uncontrolled mitochondrial $\mathrm{Ca}^{2+}$ uptake, like under conditions of MICU1 depletion, yields activation of apoptotic pathways and, ultimately, cell death (11). The importance of the ER-mitochondrial $\mathrm{Ca}^{2+}$ transfer in cancer cells was further highlighted by the finding that certain oncogenes manipulate contact sites between these two organelles thereby affecting mitochondria-associatedER membranes (MAMs) (18). In contrast the cancer testis antigen, FATE1 antagonizes cancer apoptosis by physically uncoupling the ER from mitochondria (19).

Accordingly, there is a large body of evidence that mitochondrial $\mathrm{Ca}^{2+}$ is of utmost importance for (cancer) cells homeostasis, functions, growth, migration, and, ultimately, survival. The contribution of Chakraborty et al. convincingly demonstrates that besides cancer cell survival, their glycolytic activity and chemoresistance are also critically associated with mitochondrial $\mathrm{Ca}^{2+}$ uptake (12).

\section{Mitochondrial $\mathrm{Ca}^{2+}$ uptake in cancer: the balance between energy and death}

Chakraborty et al. described a poor prognosis of cancer patient suffering from ovarian cancer with elevated expression of MICU1 (12). These data point to a protective effect of elevated MICU1 on cancer cell survival by preventing mitochondrial $\mathrm{Ca}^{2+}$ overload and, subsequently the initiation of the machinery for apoptotic cell death (Figure 1). These data further indicate that cancer cells benefit from reduced mitochondrial $\mathrm{Ca}^{2+}$ uptake, thus, illustrating the obvious risk of tumor cells for mitochondrial $\mathrm{Ca}^{2+}$ overload. Recently, cancer cells were found to exhibit a stronger tethering between mitochondria and ER in comparison to non-cancerous cells (11). While this enforced intra-organelle communication fosters e.g., mitochondrial ATP supply for the ER's protein folding machinery and, thus, meets the high energy demand of cancer cells, such settings makes them more vulnerable for mitochondrial $\mathrm{Ca}^{2+}$ overload.

Notably, cancer cells developed multiple unique strategies to protect themselves against lethal mitochondrial $\mathrm{Ca}^{2+}$ overload:

(I) Via the protein arginine methyl transferase 1 (PRMT1) MICU1 gets methylated yielding a strong sensitivity loss of the mitochondrial $\mathrm{Ca}^{2+}$ uptake machinery. In cancer cells methylated MICU1 protects from mitochondrial $\mathrm{Ca}^{2+}$ overload (14).

(II) Tumor cell physiology and plasticity is regulated 
by cancer-specific mitochondrial dynamics (20).

(III) Most cancer cells develop a unique redox handling by enhancing NADPH-dependent scavenging enzymes (21).

(IV) Cancer cells can actively untether their mitochondria from the ER (22).

(V) Cancer cells modulate ER $\mathrm{Ca}^{2+}$ release by regulating inositol-1,4,5 trisphosphate receptors (IP3R), the constitutive receptors for ER $\mathrm{Ca}^{2+}$ release (23).

(VI) The permeability of the outer mitochondrial membrane (VDAC) is regulated (24).

(VII) Cancer cell suppress mitochondrial $\mathrm{K}^{+}$-channels and its normalization promotes apoptosis and hampers cancer growth (25).

This incomplete list illustrates the flexibility of cancer cells to address the issue of keeping the balance between enough mitochondrial $\mathrm{Ca}^{2+}$ uptake to meet the cell's ATP demand while to avoid mitochondrial $\mathrm{Ca}^{2+}$ overload in order to stay clear from the initiation of apoptotic processes that ultimately would cause cancer cell death.

\section{Mitochondrial $\mathrm{Ca}^{2+}$ uptake as therapeutic target}

Many authors including Chakraborty et al. $(12,26)$ have indicated the potential of targeting mitochondrial $\mathrm{Ca}^{2+}$ uptake to fight against cancer growth. In this regard, three approaches appear most promising to be effective to introduce mitochondrial $\mathrm{Ca}^{2+}$ overload leading to apoptotic cancer cell death:

(I) Directly affecting constituents of the MCU complex yielding uncontrolled $\mathrm{Ca}^{2+}$ uptake;

(II) Manipulating the vicinity between the mitochondria and the ER resulting in an harmful enhancement of mitochondrial $\mathrm{Ca}^{2+}$ sequestration;

(III) Disturbing the main $\mathrm{Ca}^{2+}$ regulators of the ER (i.e., SERCA and IP3R) to trigger exhaustive ER $\mathrm{Ca}^{2+}$ depletion and subsequently mitochondrial $\mathrm{Ca}^{2+}$ overload.

\section{Conclusions}

While controlled mitochondrial $\mathrm{Ca}^{2+}$ uptake promotes cancer cell growth, the adequate transfer of $\mathrm{Ca}^{2+}$ into mitochondria is also of utmost importance for the proper functioning of somatic cells and tissues. Therefore, future work essentially needs to be aimed on the identification of cancer specificities in mitochondrial $\mathrm{Ca}^{2+}$ handling that can be therapeutically targeted to selectively fight cancer cells without affecting non-cancerous cells.

\section{Acknowledgments}

Funding: The authors are supported by the Doctoral College "Metabolic and Cardiovascular Disease" at the Medical University of Graz that was funded by the FWF (W 1226-B18, DKplus Metabolic and Cardiovascular Disease), the $\mathrm{PhD}$ program Molecular Medicine (MOLMED) at the Medical University of Graz, the FWF (P 28529-B27) and by Nikon Austria within the Nikon-Center of Excellence, Graz. Microscopic equipment is part of the Nikon-Center of Excellence, Graz that is supported by the Austrian infrastructure program 2013/2014, Nikon Austria Inc., and BioTechMed, Graz.

\section{Footnote}

Provenance and Peer Review: This article was commissioned and reviewed by the Section Editor Zheng Li (Department of Gynecologic Oncology, The Third Affiliated Hospital of Kunming Medical University, Kunming, China).

Conflicts of Interest: Both authors have completed the ICMJE uniform disclosure form (available at http://dx.doi. org/10.21037/tcr.2017.08.28). The authors have no conflicts of interest to declare.

Ethical Statement: The authors are accountable for all aspects of the work in ensuring that questions related to the accuracy or integrity of any part of the work are appropriately investigated and resolved.

Open Access Statement: This is an Open Access article distributed in accordance with the Creative Commons Attribution-NonCommercial-NoDerivs 4.0 International License (CC BY-NC-ND 4.0), which permits the noncommercial replication and distribution of the article with the strict proviso that no changes or edits are made and the original work is properly cited (including links to both the formal publication through the relevant DOI and the license). See: https://creativecommons.org/licenses/by-nc-nd/4.0/.

\section{References}

1. Vogelstein B, Papadopoulos N, Velculescu VE, et al. Cancer genome landscapes. Science 2013;339:1546-58. 
2. Rajagopalan H, Nowak MA, Vogelstein B, et al. The significance of unstable chromosomes in colorectal cancer. Nat Rev Cancer 2003;3:695-701.

3. Oermann EK, Wu J, Guan KL, et al. Alterations of metabolic genes and metabolites in cancer. Semin Cell Dev Biol 2012;23:370-80.

4. DeBerardinis RJ, Thompson CB. Cellular metabolism and disease: what do metabolic outliers teach us? Cell 2012;148:1132-44.

5. Warburg O. Über den Stoffwechsel der Carcinomzelle. Die Naturwissenschaften 1924;50:1131-7.

6. Mazurek S. Pyruvate kinase type M2: a key regulator of the metabolic budget system in tumor cells. Int J Biochem Cell Biol 2011;43:969-80.

7. Iqbal MA, Gupta V, Gopinath P, et al. Pyruvate kinase M2 and cancer: an updated assessment. FEBS Lett 2014;588:2685-92.

8. Vyas S, Zaganjor E, Haigis MC. Mitochondria and Cancer. Cell 2016;166:555-66.

9. Seyfried TN. Cancer as a mitochondrial metabolic disease. Front Cell Dev Biol 2015;3:43.

10. Cárdenas C, Müller M, McNeal A, et al. Selective Vulnerability of Cancer Cells by Inhibition of $\mathrm{Ca}\left({ }^{2+}\right)$ Transfer from Endoplasmic Reticulum to Mitochondria. Cell Rep 2016;14:2313-24.

11. Madreiter-Sokolowski CT, Gottschalk B, Parichatikanond W, et al. Resveratrol Specifically Kills Cancer Cells by a Devastating Increase in the $\mathrm{Ca}^{2+}$ Coupling Between the Greatly Tethered Endoplasmic Reticulum and Mitochondria. Cell Physiol Biochem 2016;39:1404-20.

12. Chakraborty PK, Mustafi SB, Xiong X, et al. MICU1 drives glycolysis and chemoresistance in ovarian cancer. Nat Commun 2017;8:14634.

13. Perocchi F, Gohil VM, Girgis HS, et al. MICU1 encodes a mitochondrial $\mathrm{EF}$ hand protein required for $\mathrm{Ca}\left({ }^{2+}\right)$ uptake. Nature 2010;467:291-6.

14. Madreiter-Sokolowski CT, Klec C, Parichatikanond W, et al. PRMT1-mediated methylation of MICU1 determines the UCP2/3 dependency of mitochondrial $\mathrm{Ca}\left({ }^{2+}\right)$ uptake in immortalized cells. Nat Commun 2016;7:12897.

15. Mallilankaraman K, Doonan P, Cárdenas C, et al.

Cite this article as: Graier WF, Malli R. Mitochondrial calcium: a crucial hub for cancer cell metabolism? Transl Cancer Res 2017;6(Suppl 7):S1124-S1127. doi: 10.21037/ tcr.2017.08.28
MICU1 is an essential gatekeeper for MCU-mediated mitochondrial $\mathrm{Ca}\left({ }^{2+}\right)$ uptake that regulates cell survival. Cell 2012;151:630-44.

16. Denton RM. Regulation of mitochondrial dehydrogenases by calcium ions. Biochim Biophys Acta 2009;1787:1309-16.

17. McCormack JG, Halestrap AP, Denton RM.

Role of calcium ions in regulation of mammalian intramitochondrial metabolism. Physiol Rev 1990;70:391-425.

18. Bittremieux M, Parys JB, Pinton P, et al. ER functions of oncogenes and tumor suppressors: Modulators of intracellular $\mathrm{Ca}\left({ }^{2+}\right)$ signaling. Biochim Biophys Acta 2016;1863:1364-78.

19. Doghman-Bouguerra M, Granatiero V, Sbiera S, et al. FATE1 antagonizes calcium- and drug-induced apoptosis by uncoupling ER and mitochondria. EMBO Rep 2016;17:1264-80.

20. Altieri DC. Mitochondria on the move: emerging paradigms of organelle trafficking in tumour plasticity and metastasis. Br J Cancer 2017;117:301-5.

21. Ciccarese F, Ciminale V. Escaping Death: Mitochondrial Redox Homeostasis in Cancer Cells. Front Oncol 2017;7:117.

22. Herrera-Cruz MS, Simmen T. Cancer: Untethering Mitochondria from the Endoplasmic Reticulum? Front Oncol 2017;7:105.

23. Cárdenas C, Miller RA, Smith I, et al. Essential regulation of cell bioenergetics by constitutive InsP3 receptor $\mathrm{Ca}^{2+}$ transfer to mitochondria. Cell 2010;142:270-83.

24. Mazure NM. VDAC in cancer. Biochim Biophys Acta 2017;1858:665-73.

25. Bonnet S, Archer SL, Allalunis-Turner J, et al. A mitochondria- $\mathrm{K}^{+}$channel axis is suppressed in cancer and its normalization promotes apoptosis and inhibits cancer growth. Cancer Cell 2007;11:37-51.

26. Madreiter-Sokolowski CT, Gyrffy B, Klec C, et al. UCP2 and PRMT1 are key prognostic markers for lung carcinoma patients. Oncotarget 2017. [Epub ahead of print]. 